\title{
QUALITY ASSURANCE IN HIGHER EDUCATION: IMPLICATIONS FOR VIETNAMESE UNIVERSITIES
}

\author{
Nguyen Thu Le Hang* \\ Faculty of English Language Teacher Education, VNU University of Languages \\ and International Studies, Pham Van Dong, Cau Giay, Hanoi, Vietnam
}

Received 19 August 2018

Revised 25 September 2018; Accepted 28 September 2018

\begin{abstract}
This papar presents the literature based research into the quality assurance practices in higher education. A framework consisting of five components - leadership and management, stakeholder engagement, internal processes, cooperation and collaboration, and culture of continuous quality improvement - will be presented. The study analyses these five components as the driving factors for quality assurance and quality improvement at the institutional level. Finally, the implications for Vietnamese higher education will be provided. Among these implications is the need to manage quality assurance as organisational change for sustainability.
\end{abstract}

Keywords: quality assurance, leadership and management, stakeholder engagement, internal processes, cooperation and collaboration, culture of continuous quality improvement

\section{Introduction}

Quality has implicitly been a concern of higher education institutions since the founding of the mediaeval universities in Europe (Van Vught \& Westerheijden, 1994). Vroeijenstijn (1995, quoted in Newton, 2006) claimed that 'the concept of quality is not new: it has always been part of the academic tradition'. In the same vein, the IIEP-UNESCO (2011) reviewed that 'quality assurance of higher education, by state authorities, collective higher education institution bodies, or higher education institutions themselves is by no

\footnotetext{
* Tel.: 84-919345269

Email: hang.nguyenthule@gmail.com
}

means a new practice and request' (p. 13). In the last decades, quality assurance has become a global concern regarding quality and standards, there has been an international market for quality assurance services, national and regional quality agencies have been established, endeavours have been invested into developing more systematic and comprehensive quality assurance approaches, and various new models and frameworks have been proposed for educational quality in higher education (IIEP-UNESCO, 2011; Boyle \& Bowden, 1997; Srikanthan \& Dalrymple, 2007). As an inevitable international tendency, various countries around the world have adopted or developed formal quality assurance 
systems, aiming at regulating and improving quality of their higher education, in response to 'competitiveness to attract students and accountability for outcomes and resources used' (Boyle \& Bowden, 1997, p. 112) to their customers and the public at large. More than ever, higher education institutions in many countries across the regions have been urged to guarantee and demonstrate their "value for money" (IIEP-UNESCO, 2011).

\section{Quality assurance frameworks and models to date}

As quality assurance adoption depends on diverse perspectives on quality dimensions, there has been no universally accepted conceptual framework for quality assurance in higher education. Quality assurance literature has seen the emergence of various models and frameworks developed for different regions at different times. More recently, various new models for educational quality management have been developed and proposed (see, for example, Cheng \& Tam, 1997; Penington, 1998; Dill, 1999; Srikanthan \& Dalrymple, 2002, 2004, 2007). For the purposes of this study, five models were selected for review. These models were identified as those that were most articulated and/or well referenced in the literature, and relevant to the Vietnamese context. Each is discussed below, in chronological order.

\subsection{The transformative model (TM)}

The transformative model was developed for European countries by Harvey and Knight (1996). It is rooted in the transformative notion that quality should focus on enhancing and empowering participants. This model highlights the development of a quality culture of continuous improvement. The authors proposed that the primary focus of the quality process should be shifted from external scrutiny to internal effective action. This continuous quality improvement process is driven from two directions: bottom-up empowerment and top-down auditing.

In Harvey and Knight's (1996) view, bottom-up empowerment leading to quality improvement requires the development of effective collegiate teams working together to identify quality targets, planning for implementation and reporting on outcomes. Bottom-up empowerment involves those participants who can affect the improvement of quality - the student, the teacher and the researcher.

Top-down auditing leading to quality improvement requires an effective external monitoring process. It takes into account a range of concerns and different stakeholder perspectives in an open, self-critical manner. Auditing operates at two levels: the internal level on a regular and comprehensive basis within the institution, and the external level, on a periodic, irregular basis, by a national or regional agency.

In a continuous quality improvement process, institutional management does not direct or manage quality but provides a context and enabling factors to facilitate quality improvement and quality culture development. The emphasis is on collegiate teamwork, the dissemination of good practice and the delegation of responsibility for quality. In the transformative model, accountability will result as a consequence of a planned and transparent quality improvement process.

2.2. The comprehensive educational quality assurance model (CEQAM)

Boyle and Bowden (1997) proposed the CEQAM based on their distillation of key ideas 
from previous literature on quality assurance and higher education culture and practice. As they viewed it, the foci and requirements for comprehensive quality assurance approaches include: 1) an overarching vision, purpose and plans of the institution; 2) effective leadership and management; 3) people (including human resource management, professional development, effective communication etc.); 4) customer orientation that includes knowledge of needs and expectations, client satisfaction and management; 5) evaluation, information and continual quality improvement; and 6) structures, policies and procedures that optimise the effectiveness of processes.

According to the authors, the model needs to be interpreted in light of the enabling conditions (including the felt need for comprehensive quality assurance, leaders' commitment to quality assurance development and quality culture, adequate resources for quality assurance etc.) and basic principles and values (such as a primary focus on continual quality improvement, and accountability as an important consequence of quality assurance). The overall model encompasses a set of key elements integrated to form a quality assurance framework, as follows:

- Key output elements: evidence-based quality improvements in student learning, and evidence for accountability requirements

- Key enabling/process elements: institutional vision, values, strategic goals; program quality assurance system; faculty development program; assessment of learning; and faculty evaluation system

- Key support systems: enabling policies, structures, resources and support groups.

The model can be perceived in an integrated way. For example, the three enabling elements program quality assurance system, faculty development, and assessment of student learning - all influence and determine the critical outcome element (i.e. quality and continuous quality improvement in student learning). There is an interrelationship between program quality assurance system and faculty development, faculty development and faculty evaluation, and assessment of learning and program quality assurance.

The distinguishing feature of this model is that it involves the key elements of educational environments that influence educational quality management. It also has continual quality improvement in student learning as its primary goal, with accountability a consequence.

\subsection{The university of learning model (ULM)}

Bowden and Marton's (1998, 2003) model has some similarities with Harvey and Knight's (1996) TM of quality. This University of Learning model (ULM), like the $\mathrm{TM}$, emphasised the enhancement of student learning and a proactive collaboration among academic teams in education delivery.

The authors examined the organisational features ofhigher education from a pedagogical perspective to facilitate a dynamic learning process. As such, the model highlights the synergetic involvement of academics in course/research teams, in developing a holistic view of students' competencies, and a collective consciousness of what is common and what is complementary. This is the basis for the academic teams to enable learners to differentiate options, and focus on the most relevant solution when facing problems and challenges in different contexts.

The authors argue that teaching, research and service are considered the core of the university system, and the ultimate goal of 
a university is to prepare the individual and the community to face future problems and turn challenges into opportunities, based on formed knowledge. In this model, there is a shift from an input-oriented educational approach to a learning-focused approach. This in turn requires HEIs to shift their focus onto policies and activities centred on student learning.

\subsection{The academic learning organisation framework (ALOF)}

Garvin (1993) argued that the concept of a learning organisation is associated with the purposeful and systematic acquisition of knowledge (both new knowledge and knowledge of its operations), and the processes and structures that facilitate these activities. Garvin's learning organisation framework was developed based on the assumption that in a competitive context, an organisation must adapt its core processes through the search for, and application of, new knowledge. A number of other authors broadly agreed: for example, Buckle (1998) viewed a learning organisation as one with increased problem-solving capability and behaviour change leading to improved performance at the individual, team and organisational level. Wick and Leon (1995) defined the learning organisation as one that 'continually improves by rapidly creating and refining the capabilities needed for future successes' (p. 299). According to these authors, the learning organisation is the ideal type of organisation in which learning is maximised.

Dill (1997, 1999) adopted Garvin's framework and further developed it into the academic learning organisation framework (ALOF). In his view universities can respond to changes in the environment (for example, pressure for academic accountability and a more competitive higher education environment) by becoming "learning organisations". Dill (1999) analysed twelve university case studies drawn from the Institute for Management in Higher Education (IMHE) project on the impact of academic quality assessment on institutional management and decision-making. From this analysis, Dill suggested the following distinctive elements of the academic learning organisation:

- Culture of evidence into academic problem-solving (systematic problem-solving employing objective measures and scientific method)

- Improved coordination of teaching units (observing basic processes to understand how they work and can be improved)

- Learning from others (seeking knowledge from colleagues that can be used for academic research and improvement of basic processes of teaching and learning)

- University-wide coordination of "learning" (developing pan-university structures for providing more effective coordination and support)

- Transferring these among academic units (Dill, 1999, pp. 148-150)

The implications of this framework confirm the adaptive responses of universities to the new environment. As Dill pointed out, the literature consistently showed that universities are internally restructuring themselves to improve academic quality, enhance innovative research, and improve entrepreneurial capacities. Dill's framework puts focus on the improvement of the teaching and learning processes. This model of learning organisations emphasises the internal processes that could enhance sustainable institutional internal quality assurance, and advocates the transformation dimension of quality. 


\subsection{The holistic model for quality management in education (HMQME)}

Srikanthan and Dalrymple (2002, 2004, 2007) developed the holistic model for quality management in education (HMQME) based on their synthesis of other quality models and approaches, including Duke (1992), Harvey and Knight (1996), Haworth and Conrad (1997), and Bowden and Marton (1998). The HMQME was grounded on the assumption that a model for quality management in higher education needs to be more holistic to meet the requirements of the two core functions of universities: service and education. The core features of this model include: 1) a clear focus on "transformation" of the learner and of the institution, "enhancing" them through the process of acquiring knowledge and skills, and ultimately "empowering" them; 2) a synergistic collaboration at the learning interface, with the underpinning idea that multi-actor collegial and supportive cultures will facilitate high quality programs; and 3) a significant commitment to improve learning at all levels, supported by senior management. A causal loop can be observed as follows: increased commitment leads to increased collaboration, which, in turn, facilitates transformation leading to improved quality outcomes.

The major elements of the model include institutional transformation for learning, teaching for transformation, assessment for transformation, quality improvement, and quality monitoring for learning. The model has various implications for the transformation of the institution, such as: a transformative type of learning (student-centred and learningoriented) should be fostered, rather than a transmissive type of learning (teachercentred and content-oriented); shared awareness of common goals and collective consciousness will make the institution a flexible dynamic organisation to cope with the changing environment; and there should be a paradigm shift regarding: 1) teaching as a key performance indicator; 2) collegial processes; and 3) the role of leadership. Similar to the CEQAM proposed by Boyle and Bowden (1997), in the HMQME, the focus of the quality system should be on improvement with accountability as a consequence.

\subsection{Summary of the reviewed frameworks and models}

Thereareboth similarities and differences in the elements covered in the reviewed quality assurance models. Regarding commonalities, in the Transformative model, the Comprehensive educational quality assurance and the Holistic models, a culture of continuous improvement is at the centre of quality assurance, with accountability as a result, and the transformation of learning is advocated. These models focus on the internal processes and the conditions that drive quality improvement at the studentstaff interface. The Transformative model, the University of learning model, the Academic learning organisation framework, and the Holistic model all emphasise the student learning experience and the dynamic collaboration of academic teams in education delivery.

In all the reviewed models, the engagement and active participation of academic staff, students, and administrators in the quality activities is highlighted. The role of stakeholder expectations and satisfaction is also an important feature of these quality assurance models. Compared to the industrial quality management models, the stakeholders involved in these educational quality models are more diversified, and the students, while the product of education, are at the same time, considered important stakeholders. 
As for the differences between the reviewed models, the Comprehensive educational quality assurance model and the Holistic model for quality appear to be more comprehensive than the others. This is because they cover more elements that constitute quality, including leadership and management, policies and procedures, cooperation and collaboration among the different units of the institution, the engagement of staff, students and administrators in the quality assurance practices, and creating a culture of continuous quality improvement with accountability as an inevitable result.

To summarise, considering the key features of the above reviewed models and frameworks of quality assurance in higher education, it can be seen that an international convergence has emerged. Quality assurance models are getting more comprehensive, addressing the two core functions of universities, service and education, taking into consideration all the involving elements of the educational environment. A clear focus of these models is on the improvement dimension of quality. This requires internal changes from the institutions, in terms of organisational structure, the role of senior management and leadership, team interaction and a shared vision within the academic community, collaboration and commitment. A culture of continuous improvement is seen to be the key to institutional success.

A substantial part of the quality assurance literature deals with quality assurance models and frameworks. It should be noted, according to Lemaitre (2002), that every model is constituted with a significant cluster of elements. Some of these are essential to the key aspects of the models, some being contextual factors without which the model cannot properly function. Therefore, when any model is imported to a new higher education environment, the cluster is broken because the context is different. In this case, the model itself needs to be redefined, taking into account such factors as the current condition of the institution and its intended goals, the requirements of the student body, the features of research, the need for academic autonomy, or the demands of external stakeholders.

\section{Quality assurance in Vietnamese higher education: adopting the regional quality assurance framework}

Vietnam is one of those countries in the Asia-Pacific region, where the government has responsibility for some areas of quality assurance, and in this scenario, it is the government's responsibility to ensure that its quality assurance practices are aligned with international best practices (APQN, 2008).

During the first decade of the twenty-first century, with the expertise from international and regional quality assurance agencies and networks, and funding from international aid agencies, the Ministry of Education and Training (MoET) undertook fundamental steps to establish a legal and regulatory framework for quality assurance in education. This included the creation of a quality assurance policy-making unit under the ministry (GDETA) and a system of instruments including sets of standards and criteria, as well as guidelines for implementation (Pham, 2012). These system level quality assurance considerations aligned with the Asia-Pacific region higher education quality assurance framework, with Chiba principles ${ }^{1}$ providing a commonly agreed reference point for

1 Chiba, Japan, 18 February 2008, workshop under Brisbane Communiqué in conjunction with the APQN annual conference, 35 participants from 17 countries discuss the establishment of principles applicable to the particular context of quality assurance in higher education in the Asia-Pacific region. 
consistency in quality assurance in the region (Pham, 2012).

In retrospect, quality assurance became a topic of discussion in the Vietnamese education development agenda in 2000. In the period 2001-2002, the MoET often referred to quality assurance as educational accreditation, due to the institutionalisation of accreditation in education. The requirement for public universities and colleges to be accredited was first put into a legal document in 2001, in Decision No. 47/2001/QĐ-TTg (MoJ, 2001). This was issued by the Prime Minister, approving the 'Planning on the network of universities and colleges in the 2001-2010 period'. It was reinforced in a subsequent legal document, Decision No. 121/2007/ QĐ-TTg (MoJ, 2007) by the Prime Minister, approving the 'Planning on the university and college network in the 2006-2020 period'. The first adopted quality assurance initiative was accreditation (of educational institutions and educational programs), founded and funded by the government in 2002 (Lam \& Vu, 2012). Accreditation standards and processes, which were developed with the USA model as a point of reference, were approved by the MoET in 2004 (Nguyen et al., 2009).

Since quality assurance in higher education was put into practice, regulations relating to this issue have been gradually integrated into the legal and regulatory system at the national level: Articles 17, 58 and 99 of the Education Law passed in 2005 relate to educational accreditation (VNA, 2005); and Part 3a in the Education Law (amended and supplemented in 2009) includes three additional articles on educational accreditation (VNA, 2009). The Higher Education Law, passed in 2012, contains one chapter (Chapter VII) on higher education quality assurance and accreditation (VNA, 2012). The government issued detailed regulatory documents and guidelines for implementation: Decree number 75/2006/ NĐ-CP (VNGO 2006)) includes Chapter II, Articles 38-40 on educational accreditation; and Decree number 31/2011/NĐ-CP (VNGO 2011), amends and supplements Articles 38 and 39 of Decree 75/2006/NĐ-CP, in Article 1, items 14 and 15. Pham (2012) reported that the MoET developed a decree guiding the implementation of the Higher Education Law, providing detailed guidelines and instructions for the implementation of Chapter VII on higher education quality assurance and accreditation. Most recently, the MoET issued circular number 12/2017/TT-BGDĐT (as of 19 May 2017) providing guidelines and instructions for higher education quality assurance and accreditation. Accordingly, the criteria for accreditation are specified based on the AUN-QA criteria set.

The enactment of comprehensive and functional legal and regulatory frameworks, as discussed above, provides Vietnamese higher education with a scaffold stipulating the requirements for quality assurance in universities, as well as other levels of education. The quality assurance practices adopted elsewhere in the higher education system could now be reinforced and officially endorsed by the government.

As a system level policy-making unit, although GDETA asserts that the focus is on improvement, rather than accountability (Pham, 2012), on their part, they can only use accreditation as a dual purpose instrument. One purpose is for the top universities that are confident in being accredited. The other is for lower- ranked universities to identify their current quality status and develop improvement plans accordingly. GDETA is aware of the fact that they can provide universities with the legal framework, impose the quality assurance model, and develop relevant policies and procedures for external 
quality assurance (accreditation implemented as a prominent activity, as outlined above). However, it is the responsibility of the universities to develop their internal quality assurance system, following Chiba principles (Pham, 2012).

In this regard, the quality assurance framework proposed in this study could serve as a well-researched framework for Vietnamese university to develop their quality assurance mechanism. The central component of this mechanism is the culture of continuous quality improvement, with accountability as a result. In the subsequent section, the proposed framework and its dimensions will be elaborated.

\section{Quality assurance framework for higher education}

This framework could be interpreted as follows: in order to have a viable quality assurance mechanism, the higher education institution(HEI), first ofall, needs to address the system level quality assurance considerations and understand the organisational theory underlying its operations. The institution needs to develop its internal quality assurance, with five dimensions contributing to its operation:

- Leadership and management, which includes the role of institutional vision, values and goals, and leadership;

- Culture of continuous quality improvement, or a quality culture;

- Stakeholder engagement in various aspects of the institution's operation;

- Internal processes whereby the institution monitors and improves its performance; and

- Cooperation and collaboration among the units within the organisational structure.

This dimension is a special one, as it links to the broader dimension of the academic learning organisation (Dill, 1999) and collaborative learning (Kezar, 2005).

With the contribution of the five dimensions to internal quality assurance, the institution will be able to achieve accountability (responding to external quality assurance) as an inevitable result of improvement (sustaining internal quality assurance and staying competitive in the higher education environment) (Dill, 1999; Harvey \& Knight, 1996).

The schematic diagram of this theoretical framework is presented in Figure 1 below. The arrow lines indicate the direction of the influence among the variables.

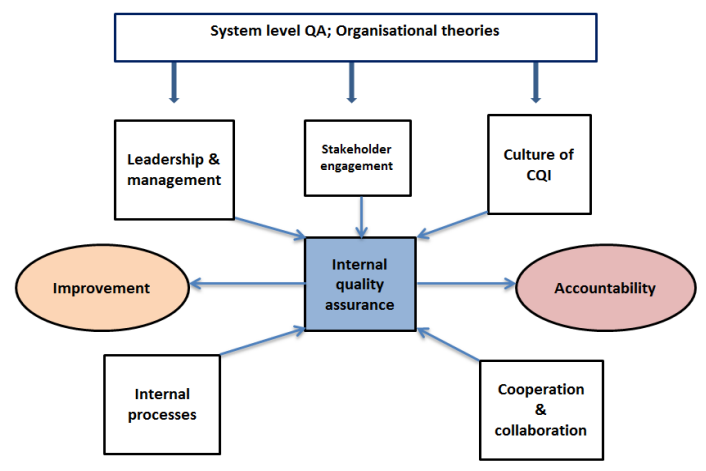

Figure 1. Diagram of the theoretical framework

\section{Factors driving quality assurance and quality improvement at the institutional level}

\subsection{Leadership and management}

\section{Dimensions of leadership}

As Meade (1997) indicated, in quality assurance in higher education, one of the major barriers to quality enhancement is the lack of leadership skills. The role of leadership in the institution's quality assurance practice can be identified using Middlehurst's (1997) framework. The first dimension of leadership is a conceptual and analytical one. In higher 
education, this dimension involves a capacity to think in new ways, to generate new ideas and perspectives, and to create a vision. According to Wick and Leon (1995), leaders must have a clear vision, commit to that vision, and consistently communicate that vision to all the staff. Therefore, all members of the organisation will be enabled to anticipate what they can contribute to help achieve the organisational goals and objectives. Leaders of the institution are at their 'vantage point' and 'best positioned to see and articulate the performance gap' (Wick \& Leon, 1995, p. 301) between the current achievements and the expected achievements of the institution.

The analytical perspective of leadership relates to the need to collect, analyse and interpret data. As Middlehurst (1997) pointed out, in the process of quality assurance, leaders need to make decisions to 'change, improve, sustain or withdraw activities' (p. 193) based on the interpretation of useful data from reviews, surveys or benchmarking activities.

The second dimension of leadership is a structural and systemic one. The leadership task at the structural level is to create structures that enable staff to improve their performance, and the organisation to improve its own performance. The systemic part of this dimension involves the capacity to attend to all the constitutive elements that have impact on the performance and operations of the institution. Fundamental changes cannot happen without this systemic leadership. In quality assurance practice in higher education, the identification of stakeholders and their interests, the search for partnerships and collaborative opportunities, and the monitoring of performance at all levels from institutional to program to individual, are examples of how this structural and systemic perspective of Middlehurst's framework can be adopted and implemented. Similarly,
Horsburgh (1999) suggested that higher education leaders should engage actively with the changes that are affecting the higher education system and learn about the approaches to quality improvement in other contexts.

The final leadership dimension in Middlehurst's (1997) framework is a motivational and behavioural one. The author recognised that appeals to academics to change their practices on the grounds of economy and efficiency are unlikely to inspire commitment beyond what can be achieved though compliance measures. As Harvey (1995) noted, the implementation of quality assurance practices carries with it implied scepticism about the quality of academics' work and a lack of trust. If the foundation is built on partnerships and mutual trust, rather than on control and policing, it is more likely to sustain the change agenda, and the chance to achieve quality improvements is potentially greater. The adoption of this perspective requires the leaders of an institution to engage staff at the motivational and behavioural levels, to facilitate sustainable change over time, even after the quality assurance event has passed (Middleshurst, 1997).

The role of leadership in the institution's quality assurance

Middlehurst and Elton's (1992) view on the role of leadership in HEIs is still applicable to the current context. That is, the leadership role needs to remain of prime importance in all scenarios: to direct and build internal commitment towards positive collective action in the face of both external pressures and internal crises; to develop and support the main functions of the institution at times without pressures; and, at all times, to provide vision, insight and strategies that can unify organisational forces. 
Regarding the specific context of quality assurance in higher education, as noted by O'Mahony and Garavan (2012), the implementation of quality assurance systems requires continuous leadership. Leaders can help increase staff awareness of quality improvement through a shared vision and purpose, and create an environment in which the organisation and its people can excel (Davies et al,. 2001; Dorfman \& House, 2004). Leadership, particularly senior leadership, commitment to, and pro-active pursuit of continuous improvement, appears to be one of the most critical factors for the success of quality [assurance] implementation in HEIs (Osseo-Asare, Longbottom \& Murphy, 2005; Papadimitriou, 2011). In support of these arguments, Kouzes and Posner (2007) proposed five practices of exemplary leadership: model the way, inspire a shared vision, challenge the process, enable others to act, and encourage the heart. These practices appear to match well with the change management process, in this case, management of quality assurance initiatives.

As Barnett (1992) argued, institutional leaders play an important role in understanding the institution's organisational structure, in identifying the compatible elements of quality assurance systems for their institution, in making them explicit, in establishing frameworks for quality assurance and enhancement, and in raising awareness that quality matters, thereby promoting a culture of quality improvement across the institution.

HEI leadership plays an important role in encouraging increased ownership of internal quality processes based on shared institutional visions and goals. When leadership is executed on the basis of transparency and fairness, and when leaders enact their quality actions, and communicate and disseminate good practices, the people involved in the quality system can be greatly motivated and engaged. If this leadership dimension is well performed and connected with other dimensions, the quality mechanism will be at its optimal operational condition.

For continuous quality improvement, the role of leaders is vital, specifically academic leaders at school and faculty levels. These leaders get involved in the enhancement of curriculum design and renovation, improving students' learning and experience, and monitoring course quality and staff performance.

\subsection{Quality culture}

Although there is no universally accepted meaning of the concept, the culture of an organisation is associated with shared values, beliefs, norms, assumptions, and meanings of individuals participating in the organisation (Tierney, 1988; Barnett, 1992). Harvey and Knight (1996) characterised the governing culture in higher education as collegialism, based on shared decision-making, integrity and commitment to knowledge. Quality culture is the enabling environment in which the HEI implements its quality assurance practices.

\section{Types of quality culture}

Harvey and Stensaker (2008) used a cultural theory framework, inspired by Douglas (1982), Thompson et al. (1990) and Hood (2000), to categorise quality culture into the following four ideal-types: responsive, reactive, regenerative and reproductive.

First, a responsive quality culture is led by external demands, such as governmental imperatives or an agency requirement for compliance. The responsive mode takes these demands as opportunities to review the institution's practices and explore 
how to make the policies and compliance requirements beneficial to internal improvement. The responsive mode will have an improvement quality agenda while addressing accountability issues.

Second, a reactive quality culture reacts to external demands, rather than engages with them. The reactive mode tends to be driven by compliance and accountability and works better when there is a reward. The quality culture is likely to be externally managed and imposed, with little or no sense of ownership. This type of quality culture appears to be less engaging than the first type.

Third, a regenerative quality culture is focused on internal improvement while being fully aware of external requirements. This dynamic mode has a coordinated plan for improvement and continuously reconceptualises its practices. The regenerative mode will presume that its continuous improvement agenda represents a form of accountability. It embraces the learning-organisation approach, stimulating collaborative learning opportunities, reflective learning and benchmarking possibilities.

Fourth, a reproductive quality culture reproduces the existing situation, aimed at minimising the impact of external factors. The reproductive mode is focused on what the institution and its units do best or what it is rewarded for. Established norms are preferred, rather than reconceptualised core values or future goals. This quality culture lacks transparency and accommodates takenfor-granted practices. A sense of "a job well done" is maintained in this culture.

As Harvey and Stensaker (2008) argued, these four types of quality culture can be found in any HEI setting and serve as a starting point for specific implications for each institution's quality assurance mechanism, with regard to the interaction between structure and culture.

In conclusion, quality culture is one of the necessary conditions for preparing HEIs to handle external demands and improve internal quality and governance. It could be a tool for reflecting on current practices, identifying possible challenges, and conceptualising future goals (Harvey \& Stensaker, 2008). It is a demanding task to achieve an effective quality culture as it requires trans-institutional commitment and involvement (Gordon, 2002).

\subsection{Stakeholder engagement}

One of the significant trends affecting higher education in many countries is the increased attention to the changing needs of society and the expectations of employers (Conway et al., 1994; Birnbaum, 2000; Vidovich, 2002). This increased awareness is reflected in the enhanced involvement of stakeholders in the decision-making and quality assurance processes in HEIs in many countries.

According to a classification by Srikanthan and Dalrymple (2003), there are four major groups of stakeholders: providers (funding bodies and community); users of products or courseware (current and prospective students); users of outputs graduates (employers); and the employees of the sector (academic staff and administrators). These authors relate the interpretations of quality developed by Harvey and Green (1993) to their own classification.

Although there are differences in the categories of stakeholders identified, there is agreement that stakeholders are those who have direct or indirect influence on the development of an HEI. Which key stakeholders will be invited to join the quality 
debate depends on the types of education quality processes in each specific higher education context.

Why should stakeholders be engaged in the quality mission?

Regarding the role of stakeholders in higher education management, Srikanthan and Dalrymple (2007) stated that any model of management in any organisation could only succeed if it represents the shared values of the stakeholders.

One of the reasons for the increased popularity of stakeholders in the quality research is that different key stakeholders bring different perspectives of quality and quality systems to HEIs (Srikanthan \& Dalrymple, 2003). As such, the first group (providers) view quality as value for money (Harvey \& Green, 1993); quality is represented in the effective utilisation of funding leading to satisfactory delivery of services and products. The second group (users of products) consider quality as excellence (Harvey \& Green, 1993); the products should be of comparatively high standards, as revealed by quality audit reports, promising advantage in career prospects and guiding student choice. For the third group (users of outputs), quality is fitness for purpose (Harvey \& Green, 1993); graduates are equipped with the required competencies to handle prospective jobs. The fourth group (employees of the sector) interprets quality as perfection or consistency (Harvey \& Green, 1993), as they require a high level of job satisfaction, including remuneration, recognition and the assurance of standards, norms and core ethos.

Westerheijden et al. (2013) also claimed that by bringing different expectations, perspectives and requirements to bear on quality, these stakeholders may enrich the debate on quality in the institution. If they focus on a single dimension (e.g. employers merely expect immediately usable skills from the graduates), then their contribution to the HEI quality debate would be less enriching. However, one condition for stakeholders to share their perspectives and join in the quality debate is the guaranteed access to HEIs' issues.

In what areas of higher education could stakeholders be involved?

Stakeholders have been involved in many stages of the education process and several activities that contribute to the assurance of higher education quality. For instance, Cornway et al. (1994) emphasised that stakeholders play an important role in the strategic planning processes of an institution and the terms that are consistent with these people would determine the survival of the institution. In order to prepare for the increasingly competitive environment, an institution should have successful strategies to deliver the right products and services. These strategies could be developed based on an understanding of the needs and wants of customers and the market (Conway et al., 1994). Thus, the involvement of stakeholders who have such knowledge and understanding is crucial.

In their case study of seven countries, Westerheijden and his team (2013) reported on a number of activities in which stakeholders are involved. First, the authors noted that key stakeholders are involved in decisionmaking bodies in HEIs, bringing in their socially-oriented views. Second, the authors commented on the pervasive professional influence of stakeholders on curriculum review and quality assurance. Good practices could be found in almost all case-study countries. For example, stakeholders from the business world have some influence on course content and thesis foci through their involvement in teaching activities, or, professionals from 
different expertise areas teach part-time and bring immediate relevance to the classroom learning. The influence of external stakeholders is reflected through such traditional channels as guest lectures, excursions and field trips; or through more up-to-date channels such as placements, joint projects or theses in specific fields. The informal contacts between external stakeholders and academic staff provide the latter group with ideas that they can reflect on and use to make necessary decisions and changes in terms of course content or teaching methods.

Regarding education quality work, Westerheijden et al. (2013) also observed that a good number of external professionals are involved in the evaluation of pedagogical processes and internal quality assurance processes at the institutional level. Also, the quality assurance agencies require that external stakeholders are consulted for curriculum review processes. This paves the avenue for HEIs' movement towards market influence.

As key stakeholders of the university, the voices of students as agents for change and improvement in learning and teaching should be recognised. Their perspectives should be counted in the assessment of quality at the institution (Lagrosen et al., 2004; Shah \& Jarzabkowski, 2013).

\subsection{Cooperation and collaboration}

The link between the leadership dimension and this cooperation and collaboration dimension is reflected in the collaborative development and implementation of the institutional strategic plan. This should clearly define goals in the core areas of research, teaching and learning. As suggested by Shah and Jarzabkowski(2013), in the self-regulating university environment, the institutional strategic plan should be supported by a research plan and a teaching and learning plan that provide guidelines for operationalisation. This should entail plans from academic faculties/schools and administrative units to put the strategic plan into operation on a dayto-day basis. Careful strategic planning has become crucial to strengthening universities' capacity to innovate their research, teaching and learning, to align strategy with amendments to government policies and trends in the external environment, and to respond to unexpected needs.

\section{Cooperation among units}

An institution's performance depends, to a considerable extent, on its internal structure and functioning. That is to say, if the internal structure does not work well, the institution will face challenges in achieving its targeted goals and outcomes. With the responsibility for implementing the goals and strategic plans of the institution, organisational unit performance has an impact on the whole institution's performance. This, according to Yorke (2000), explains the trend of organisational units being increasingly required to demonstrate how their activities support institutional plans and policies. Nevertheless, due to the varied nature of HEIs in terms of how loosely coupled their internal units are, or how autonomous these units are operating, the relationship between whole institutional functioning and organisational unit effectiveness is not explicit (Yorke, 2000).

As Sporn (2007) pointed out in her analysis of the new direction of higher education management, if core contributions of all academic and administrative units in a university are clearly defined, in the form of contracts between the leadership and basic units, the institutional performance will be more efficient and effective. For academic units, the focus will be on teaching and 
research. For administrative units, the focus will be on functional areas such as information technology (IT), libraries, or marketing. Such procedures as management by objectives through contracts, goal setting and strategic planning as a basis for resource allocation and output control, are being applied in higher education.

Within the context above, as described by Sporn (2007), the cooperation between basic university units is very important, as an individual unit is not likely to implement its operations and achieve set goals if it is not connected to, or in collaboration with, other units. Between academic units, collaboration includes shared teachingand learninginitiatives and joint research projects. Between academic and administrative units, cooperation includes support for the implementation of policy and procedures. Rhoades (1998) introduced the term 'professional managers' when describing the trend of professionalisation of higher education. Similarly, Sporn (2007) observed the development of professional support in many institutions. Examples include teaching centres designed to assist academic faculties to improve their course development and teaching methodologies, or multi-media officers who advise faculty staff about applying technology transfer to their teaching or translating their research into marketable products. These professional support activities represent and promote the cooperation and collaboration between university units.

As globalisation brings increased competitiveness to the higher education sector, universities are moving towards more market-oriented and entrepreneurial models. With governance being in the hands of the top leadership and administration being professionally managed, the power balance between academic faculties and administration can only be achieved when both groups are accountable, based on mutually agreed indicators and measures (Sporn, 2007; Amey et al., 2007). This condition is an important dimension of any quality assurance mechanism in higher education institutions.

\section{Collaborative learning}

Cooperation among organisational units contributes to the improved performance of the whole institution. Likewise, academic collaboration across the university network enhances the quality of teaching, learning and research. Srikanthan and Dalrymple (2002) claimed that collaboration is the key requirement for improvement of educational delivery.

Another study by Kezar (2005), among a very limited number of studies on collaboration at universities, highlights that if institutions redesign their organisational contexts to accommodate collaboration, they might be more responsive to external pressures. The major elements of Kezar's model of a collaborative university are:

Mission statements include the concept of collaboration, which is integrated into all the institution's work. It is reinforced through communication, and in public speeches by leaders and managers referring to the mission and collaborative work.

Networks provide a vehicle for ideas to flow and to gain momentum and energy to sustain the collaboration. Networks overcome resistance to new structures or processes on campus and inspire more people to join in the collaborative work. Networks have to be cultivated before attempts are made to conduct collaborative work. Typical activities of network building include orientation for a new faculty, a leadership series for faculty and staff, social events and academic symposia.

Integrating structures help redesign the organisational context for sustained 
collaboration, when the idea (mission) and the people (network) are in place. The exemplary structure requires a central unit in charge of fostering collaboration, cross-campus high profile institutes and centres, and new accounting, computer and budgetary systems.

Rewards and incentives help promote collaboration, they help a new faculty to adopt an alternative approach to faculty work (i.e. collaborative work).

Sense of priority from the people in senior positions. Collaboration is a signalled priority when it is discussed by senior administrators, connected to the strategic objectives of the institution, written in strategic plans, accreditation reports and board correspondence, and is modelled by senior executives.

External groups such as sponsors, accrediting agencies, national coordinating boards, and stakeholders from business and industries create pressures for collaboration. The pressure from accreditors is the major source of support for a faculty that believes in collaboration; and motivates administrators, as poor accreditation affects the institution's reputation. The pressure from business and industry, as collaboration is needed in the workplace, has a powerful influence on certain disciplines, leading to transformed curricula.

Learning and conversations among colleagues, and informal information sharing about the benefits of collaboration, gradually confirm the message that collaboration enhances faculty work. A mechanism is needed to allow people to interact, such as a staff dining area or staff retreats.

These features, identified by Kezar in 2005 , are still applicable to many HEIs, especially in developing countries. Sustained collaboration in the institution not only strengthens teaching, learning and research efforts, but will also pay off as better public recognition.

\subsection{Internal processes}

In the operationalisation of the institutional strategic plan, the achievement of strategic goals requires a strong and reliable operational system. This system is dedicated to managing risk and assuring and improving quality across all areas of the university (Shah \& Jarzabkowski, 2013). It supports leadership and management through a robust system of internal processes, in the form of policies and procedures, and indicators and measures that help with regular performance evaluation in key areas. These processes, according to Shah and Jarzabkowski (2013), reflect higher education threshold standards and risk indicators. When these processes are in place, the institution can set and achieve its own goals, while being compliant with those higher education threshold standards.

Whether the institution is focused on external quality assurance compliance or internal quality improvement, it needs to develop professional administration and education support structures, to create new policies and procedures, and systems for managing data and information on educational performance and quality (Stensaker 2003; Westerheijden, Hulpiau \& Waetens, 2007). While compliance- led quality assurance aims at getting policies and procedures right, improvement- led quality assurance aims at ensuring these are effective and implemented with consistency.

Harvey (2002a) argued that when the institution focuses on continuous improvement and adopts process-driven quality assurance, the internal processes will generate their own performance indicators. Such indicators will be owned by the institution and will measure real improvements. However, when processes 
become more elaborate, place more demands on staff and become routinised, they lose their improvement potential (Harvey, 2002b). This might be due to the fact that administrative loads (e.g. the time and effort needed for form filling and evidence recording for accountability) may impinge on the time required for academic tasks or collaboration to improve teaching, learning and research quality.

Discussion of internal processes or policies and procedures (P\&P) has gained popularity in the business management literature, with researchers arguing about the importance of these matters in the operationalisation of HEIs. However, there is very limited literature on such aspects as how institutions develop their internal processes; what enables or hinders the effectiveness of the internal processes; whether or not there are commonly applied internal processes; and whether or not HEIs have included internal processes in their quality assurance mechanisms.

\section{Implications for Vietnamese higher education}

The above elaborated components of the quality assurance framework (leadership and management, quality culture, stakeholder engagement, cooperation and collaboration, and internal processes) can be viewed as the key dimensions of the quality assurance mechanism required for any HEI. As such, educational quality can be assured and enhanced when:

- Leaders and managers make sure that quality assurance is written into official documents, such as the institutional mission and strategic plan; signal quality assurance as a priority in the institution's development agenda; and sustain their engagement in, and commitment to, quality improvement by showcasing their quality thinking and quality enactments.

- A culture of continuous quality improvement is created and nurtured in the institution, by the commitment of leaders; the increased awareness of all staff members of the need to practice quality assurance; and the enabling support structures and processes.

- Key stakeholders, especially those for whom the educational quality of the institution really matters (funding agencies, staff and students), and those who have relevant expertise and experience, are actively engaged in the decision-making process, including such educational and pedagogical aspects as curriculum renovation, new degree program development, partnerships and internships.

- The HEI promotes cooperation and collaboration and advocates transformative learning; and there is favourable cooperation and collaboration among organisational units, in the operationalisation of institutional functions and in the pursuit and improvement of teaching, learning and research endeavours.

- There are enabling internal processes in place, accompanied by performance indicators for measuring real improvements. The interaction between and among these dimensions varies according to the specific context of an institution. However, in total, they constitute a comprehensive mechanism for quality assurance in HEIs.

As implementing quality assurance initiatives is still a new phenomenon in Vietnam (Nguyen et al., 2009; Pham, 2012; Dao, 2014; Lam \& Vu, 2012), how to support and sustain this important change is a critical concern for all change agents involved.

One common feature of the reviewed change management process models (Crosby, 1984; Anderson \& Anderson, 2001; Kotter 
\& Cohen, 2002; Boman \& Deal, 2008) is that change implementation is not a one-off process, but a continuous process. Making change "stick" is equally important (Senge et al., 1999; Palmer, Dunford \& Akin, 2009). To facilitate sustainable change, a new culture must be created, embedding change in routine organisational practices. In this respect, researchers highlight the importance of the critical role of change leadership, communication and training, realignment of roles and systems, resolution of conflicts and resistance, and short-term achievement celebrations (Graetz et al., 2011; Palmer et al., 2009; Bolman \& Deal, 2008; Anderson \& Anderson, 2001).

Commenting on the need for organisations to sustain change, Palmer, Dunford and Akin (2009) claimed that 'sustaining change is necessary to ensure that some time after they are implemented, things do not quietly drift back to how they used to be. Sustaining change is about how to make it stick, how to make it a core feature of how work will occur' (p. 13). Therefore, it is recommended that Vietnamese universities should realign their quality assurance policies and practices, mobilise all possible resources, and optimise their systems, aiming ultimately at strengthening their internal quality assurance. Having a sustainable and robust internal quality assurance mechanism represents a positive step towards enhanced institutional capacity and competitiveness. Quality assurance, whether externally imposed or internally driven, would then function as a means to an end.

\section{Conclusion}

In this article, the proposed framework for quality assurance in higher education has been presented. It was conceptualised based on the existing quality assurance models and frameworks, with reference to organisational theories in higher education and the organisational theories reframed for change management. The factors that drive external quality assurance and internal quality improvement at the institutional level - the dimensions of this theoretical framework - have been further analysed. Finally, the implications for Vietnamese universities to sustain their quality assurance initiative have been proposed.

The ultimate purpose of the quality assurance initiative is to help universities better themselves. Therefore, it should be viewed as an internally-driven change. Symbolic compliance or concealment should not be desirable practices, no matter how much they appear to improve the external image. In the end, it is true quality that counts.

\section{References}

Amey, M. J., Eddy, P. L., \& Ozaki, C. C. (2007). Demands for partnership and collaboration in higher education: A model. New Directions for Community Colleges, 2007(139), 5-14. doi: 10.1002/cc.288.

Anderson, D., \& Anderson, L. A. (2001). Beyond Change Management. San Francisco, CA: JosseyBass/Pfeiffer.

APQN. (2008). Higher education quality assurance principles for the Asia-Pacific region. Paper presented at the APQN Annual conference, Chiba, Japan.

Barnett, R. (1992). Improving Higher Education: Total Quality Care. Buckingham: SRHE and Open University Press.

Birnbaum, R. (2000). Management fads in higher education: Where they come from, What they do, Why they fail. Chichester: John Wiley.

Bolman, L. G., \& Deal, T. E. (2008). Reframing Organizations: Artistry, Choice, and Leadership. (4th ed.). San Francisco, CA: Jossey-Bass.

Bowden, J., \& Marton, F. (1998). The University of Learning: Beyond quality andcompetence in university education. London: Kogan Page.

Bowden, J., \& Marton, F. (2003). The university of learning: beyond quality and competence.New York: Routledge. 
Boyle, P., \& Bowden, J. A. (1997). Educational Quality Assurance in Universities: an enhanced model. Assessment and Evaluation in Higher Education, 22(2), 111-121.

Buckle, B. (1998). Practical steps towards a Learning Organization: Applying academic knowledge to Improvement and Innovation in business process. The Learning Organization, 5(1), 15-23.

Cheng, Y. C., \& Tam, W. M. (1997). Multi-models of quality in education. Quality Assurance in Education, 5(1), 22-31.

Conway, T., Mackay, S., \& Yorke, D. (1994). Strategic planning in higher education: Who are the customers. International journal of educational Management, 8(6), 29-36.

Crosby, P. B. (1984). Quality Without Tears: The Art of Hassle-Free Management. New York: McGraw-Hill.

Dao, K. V. (2014). Key challenges in the reform of governance, quality assurance, and finance in Vietnamese higher education - a case study. Studies in Higher Education, 1-16. doi: 10.1080/03075079.2013.842223

Davies, J., Hides, M. T., \& Casey, S. (2001). Leadership in higher education. Total Quality Management, 12(7-8), 1025-1030.

Dill, D. D. (1997). Higher education markets and public policy. Higher education policy, 10(3-1), 167-185.

Dill, D. D. (1999). Academic accountability and university adaptation: The architecture of an academic learning organisation. Higher Education, 38, 127-154.

Dorfman, P. W., \& House, R. J. (2004). Cultural Influences on Organizational Leadership. Culture, Leadership and Organizations: the GLOBE study of 62 societies (pp. 51-73). Thousand Oaks, California: Sage Publications.

Douglas, M. (1982). Cultural bias. In M. Douglas (Ed.), In the active voice. (pp.183-254) London: Routledge and Kegan Paul.

Duke, C. (1992). The Learning University. Towards a New Paradigm? The Cutting Edge Series. ERIC.

Garvin. (1993). Building a learning organization. Harvard Business Review, 71(4), 78-84.

Gordon, G. (2002). The roles of Leadership and Ownership in Building an Effective Quality Culture. Quality in Higher Education, 8(1), 97-106. doi: 10.1080/13538320220127498.

Graetz, F., Rimmer, M., Smith, A., \& Lawrence, A. (2011). Managing Organisational Change- (3rd Australasian ed.). Milton Qld: John Wiley \& Sons Australia.

Harvey, L. (1995). Beyond TQM. Quality in Higher Education, 1(2), 123-146.

Harvey, L. (2002a). The end of quality? Quality in Higher Education, 8(1), 5-22.
Harvey, L. (2002b). Evaluation for what? Teaching in Higher Education, 7(3), 245-263.

Harvey, L., \& Green, D. (1993). Defining Quality. Assessment and Evaluation in Higher Education, $18(1), 9-34$.

Harvey, L., \& Knight, P. T. (1996). Transforming Higher Education. London: SRHE and Open University Press.

Harvey, L., \& Stensaker, B. (2008). Quality culture: understandings, boundaries and linkages. European Journal of Education, 43(4), 427-442.

Haworth, J. G., \& Conrad, C. F. (1997). Emblems of Quality in Higher Education. Developing and Sustaining High-Quality Programs. ERIC.

Hood, C. (2000). The art of the state: Culture, rhetoric, and public management: Oxford University Press.

Horsburgh, M. (1999). Quality Monitoring in Higher Education: the impact on student learning Quality in Higher Education, 5(1), 9-25.

IIEP-UNESCO. (2011). External quality assurance: options for higher education managers: Training modules. IIEP- UNESCO

Kezar, A. (2005). Moving from I to, reorganizing for collaboration in higher education. Change: The Magazine of Higher Learning, 37(6), 50-57.

Kotter, J. P., \& Cohen, D. S. (2002). The Heart of Change: Real Life Stories of How People Change Their Organizations. Boston: Harvard Business School Press.

Kouzes, J. M., \& Posner, B. Z. (2007). The Leadership Challenge. (4th ed.). San Francisco: Jossey-Bass.

Lagrosen, S., Seyyed-Hashemi, R., \& Leitner, M. (2004). Examination of the dimensions of quality in higher education. Quality Assurance in Education, 12(2), 61-69. doi:10.1108/09684880410536431.

Lam, T. Q., \& Vu, P. A. T. (2012). The development of Higher Education, and its Quality Assurance, in Vietnam. In D. Acedo, D. Adams \& S. Popa (Eds.), Quality and Qualities: Tensions in Education Reforms (pp. 125-142). Rotterdam: Sense Publishers.

Lemaitre, M. J. (2002). Quality as politics. Quality in Higher Education, 8(1), 29-37.

Meade, P. H. (1997). Challenges facing universities: Quality leadership and the management of change. Dunedin: University of Otago.

Middlehurst, R. (1997). Reinventing Higher Education: the leadership challenge. Quality in Higher Education, 3(2), 183-198.

Middlehurst, R., \& Elton, L. (1992). Leadership and management in higher education. Studies in Higher Education, 17(3), 251-264.

MoJ. (2011). Decision No. 47/2001/QD-TTg by the Prime Minister of the Government: Approving the planning on the network of universities and colleges in the 2001-2010 period. 
MoJ. (2007). Decision No. 121/2007/QĐ-TTg by the Prime Minister of the Government: Approving the planning on the university and college network in the 2006-2020 period.

Newton, J. (2006). What is quality? Paper presented at the 1st European Forum.

Nguyen, K. D., Oliver, D. E., \& Priddy, L. E. (2009). Criteria for Accreditation in Vietnam's Higher Education: Focus on Input or Outcome? Quality in Higher Education, 15(2), 123-134.

O’Mahony, K., \& Garavan, T. N. (2012). Implementing a quality management framework in a higher education organisation: A case study. Quality Assurance in Education, 20(2), 184-200.

Osseo-Asare, A. E., Longbottom, D., \& Murphy, W. D. (2005). Leadership best practices for sustaining quality in UK higher education from the perspective of the EFQM Excellence Model. Quality Assurance in Education, 13(2), 148-170.

Palmer, I., Dunford, R., \& Akin, G. (2009). Managing Organizational Change: a multiple perspective approach. Boston: McGraw-Hill Irwin.

Papadimitrious, A. (2011). Reforms, Leadership and Quality Management in Greek Higher Education. Tertiary Education and Management, 17(4), 355-372.

Penington, D. (1998). Managing quality in higher education institutions of the 21 st century: a framework for the future. Australian Journal of Education, 42(3), 256-270.

Pham, T. X. (2012). Overview of quality assurance and quality accreditation of education in Vietnam. Report to the National committee for communication. Hanoi: General Department of Educational Testing and Accreditation, Ministry of Education and Training.

Senge, P., Kleiner, A., Roberts, C., Ross, R., Roth, G., \& Smith, B. (1999). The dance of change. New York: Doubleday.

Shah, M., \& Jarzabkowski, L. (2013). The Australian higher education quality assurance framework. Perspectives: Policy and Practice in Higher Education, 17(3), 96-106.

Sporn, B. (2007). Governance and Administration: Organizational and structural trends. In J. F. F. James \& G. A. Philip (Eds.), International Handbook of Higher Education (pp. 141-157). Springer.

Srikanthan, G., \& Dalrymple, J. (2002). Developing a Holistic Model for Quality in Higher Education. Quality in Higher Education, 8(3), 215-224.

Srikanthan, G., \& Dalrymple, J. (2003). Developing alternative perspectives for quality in higher education. International Journal of
Educational Management, 17(3), 126-136. doi:10.1108/09513540310467804.

Srikanthan, G., \& Dalrymple, J. (2004). A synthesis of a quality management model for education in universities. International Journal of Educational Management, 18(4), 266- 279.

Srikanthan, G., \& Dalrymple, J. (2007). A conceptual overview of a holistic model for quality in higher education. International Journal of Educational Management, 21(3), 173-193.

Stensaker, B. (2003). Trance, transparency and transformation: The impact of external quality monitoring on higher education. Quality in Higher Education, 9(2), 151-159.

Thompson, M., Ellis, R., \& Wildavsky, A. (1990). Cultural theory. Boulder: Westview Press.

Tierney, W. G. (Ed.). (1998). The Responsive University: Restructuring for High performance. Baltimore, MD: The Johns Hopkins University Press.

Van Vught, F. A., \& Westerheijden, D. F. (1994). Towards a general model of quality assessment in Higher Education. Higher Education, 28(3), 355371.

Vidovich, L. (2002). Quality assurance in Australian higher education: Globalisation and "steering at a distance". Higher Education, 43, 391-408.

VNA. (2005). Education Law (No. 38/2005/QH11 of June 14, 2005).

VNA. (2009). Law: Amending and Supplementing a number of Articles of the Education Law (No. 44/2009/QH12 of November 25, 2009).

VNA. (2012). Law on Higher Education (No. 08/2012/ QH13).

VNGO. (2011). Decree No. 31/2011/NĐ-CP: Amending and supplementing a number of articles of the Government's decree No. 75/2006/NĐ-CP.

Westerheijden, D. F., Epping, E., Faber, M., Leisyte, L., \& De Weert, E. (2013). Stakeholders and Quality Assurance. Journal of the European Higher Education Area, 4, 71-85.

Westerheijden, D. F., Hulpiau, V., \& Waeytens, K. (2007). From Design and Implementation to Impact of Quality Assurance: An Overview of Some Studies into what Impacts Improvement. Tertiary Education and Management, 13(4), 295-312. doi: 10.1080/13583880701535430.

Wick, C. W., \& Leon, L. S. (1995). From Ideas to Action: Creating a Learning Organization. Human Resource Management, 34(2), 299-311.

Yorke, M. (2000). Developing a quality culture in higher education. Tertiary Education and Management, 6(1), 19-36. 


\title{
ĐẢM BẢO CHẤT LƯợNG GIÁO DỤC ĐẠI HỌC: NHỮNG BÀI HỌC ỨNG DỤNG CHO CÁC TRƯỜNG ĐẠI HỌC CỦA VIỆT NAM
}

\author{
Nguyễn Thu Lệ Hằng \\ Khoa Su phạm tiếng Anh, Trương Đại học Ngoại ngũu, ĐHQGHN, \\ Phạm Văn Đồng, Cầu Giáy, Hà Nội, Việt Nam
}

Tóm tắt: Bài báo này trình bày nghiên cứu dựa trên tổng thuật tài liệu về đảm bảo chất lượng giáo dục đại học, từ đó xây dựng một khung đảm bảo chất lượng gồm 5 thành tố cơ bản là lãnh đạo và quản lý, sự tham gia của các bên liên quan, các qui trình nội bộ, hợp tác và phối hợp, và văn hoá không ngừng cải tiến chất lượng. Nghiên cứu đã phân tích 5 thành tố này như những yếu tố thúc đẩy đảm bảo chất lượng và nâng cao chất lượng ở các trường đại học. Cuối cùng, bài viết đưa ra những bài học ứng dụng cho các trường đại học của Việt Nam, trong đó có sự cần thiết phải quản lý đảm bảo chất lượng như một thay đổi của tổ chức nhằm đạt được sự bền vững.

Tù khoá: đảm bảo chất lượng, lãnh đạo và quản lý, sự tham gia của các bên liên quan, qui trình nội bộ, hợp tác và phối hợp, văn hoá không ngừng cải tiến chất lượng 